\title{
Erythema Ab Igne and Malignant Transformation to Squamous Cell Carcinoma
}

\author{
Elizabeth G. Wilder, MD; Jillian H. Frieder, MD; M. Alan Menter, MD
}

\section{PRACTICE POINTS}

- Erythema ab igne (EAl) is a cutaneous reaction in response to prolonged exposure to infrared heat sources at temperatures insufficient to induce a burn.

- Common infrared heat sources include open fires, coal stoves, heating pads, laptop computers, and electric space heaters.

- Although considered a chronic pigmentary disorder, EAI rarely can progress to malignant transformation, including squamous cell carcinoma. Patients with EAI should be monitored long-term for malignant transformation.

\section{Case Report}

A 67-year-old Black woman presented with a longstanding history of pruritus and "scaly thick bumps" on the lower extremities. Upon further questioning, she reported a 30-year history of placing her feet by an electric space heater and daily baths in "very hot" water. A review of systems and medical history were unremarkable, and the patient was not on any medications. Initial physical examination of the lower extremities demonstrated lichenified plaques and scattered, firm, ulcerated nodules surrounded by mottled postinflammatory hyperpigmentation with sharp demarcation at the midcalf bilaterally (Figure 1).

A punch biopsy of a representative hyperkeratotic plaque on the right dorsal foot demonstrated full-thickness, atypical, keratinizing epithelial cells of the epidermis with moderate nuclear pleomorphism and numerous mitotic figures. The histologic features were consistent with a squamous cell carcinoma (SCC) arising in the setting of changes of erythema ab igne (EAI). The patient initially was managed with topical 5-fluorouracil under occlusion and was advised to avoid exposing the affected area to heat.

Subsequently, the patient was shown to have multiple actinic keratoses and SCCs, both in situ and invasive, within the areas of EAI (Figure 2). The patient had no actinic keratoses or other cutaneous malignant neoplasms elsewhere on the skin. Management of actinic keratoses, SCC in situ, and invasive SCC on the lower extremities included numerous excisions, treatment with liquid nitrogen, and topical 5-fluorouracil under occlusion. The patient continues to be monitored frequently.

From Baylor University Medical Center, Division of Dermatology, Dallas, Texas.

The authors report no conflict of interest.

Correspondence: Jillian H. Frieder, MD, 3900 Junius St, Ste 125, Dallas, TX 75246 (jhfrieder@gmail.com).

doi: $10.12788 /$ cutis. 0145 

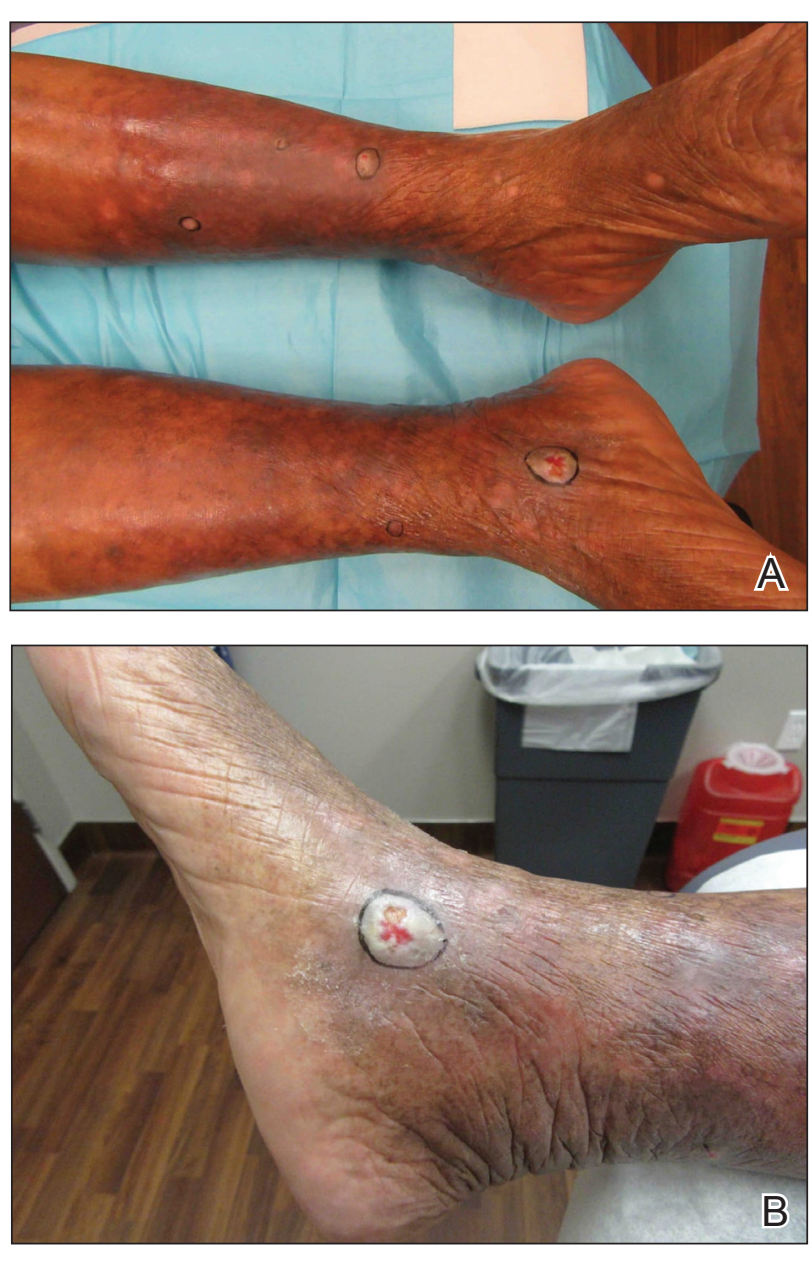

FIGURE 1. A, Scattered scaly papules and plaques with 1 ulcerated nodule on the right medial ankle (invasive squamous cell carcinoma). The lower extremities showed reticulated erythema and hyperpigmentation extending from the dorsal feet to the mid to lower leg. B, An ulcerated nodule on the right medial foot with surrounding mottled hyperpigmentation.

\section{Comment}

Presentation of EAI-Erythema ab igne is a cutaneous reaction resulting from prolonged exposure to an infrared heat source at temperatures insufficient to cause a burn $\left(37^{\circ} \mathrm{F}\right.$ to $113{ }^{\circ} \mathrm{F}\left[2.78{ }^{\circ} \mathrm{C}\right.$ to $\left.\left.45^{\circ} \mathrm{C}\right]\right)$. Initially presenting as transient blanchable erythema, chronic heat exposure induces persistent areas of reticular erythema, often accompanied by hyperpigmentation, epidermal atrophy, and telangiectases. ${ }^{1}$ Erythema ab igne is most commonly reported on the anterior shins, inner thighs, and back, and it is historically associated with open fires and coal stoves. More recently, other implicated causes include heating pads, laptop computers, heated furniture, and electric space heaters. ${ }^{2,3}$ Erythema ab igne often is asymptomatic but can present with pruritus and a burning sensation. Treatment involves removal of the inciting heat source, which might allow resolution of early-stage lesions. Long-term exposure leads to permanent skin
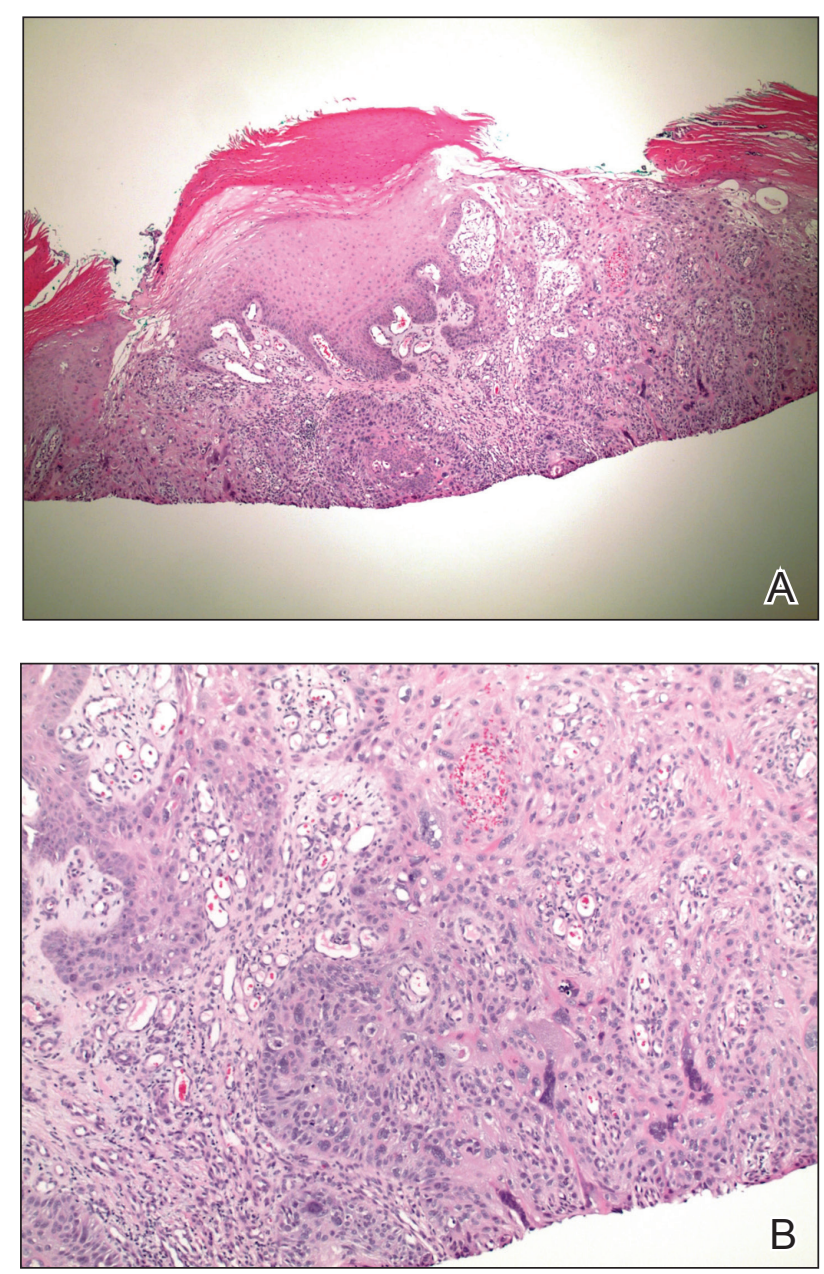

FIGURE 2. Invasive squamous cell carcinoma. A, Histopathology demonstrated an atypical proliferation of keratinizing epithelial cells extending from the epidermis and discontinuously into the dermis. Nuclear pleomorphism was noted ( $\mathrm{H} \& \mathrm{E}$, original magnification $\times 40$ ). $B$, Dilated superficial dermal blood vessels represented possible background changes observed in erythema ab igne (H\&E, original magnification $\times 100$ ).

discoloration and on occasion predisposes patients to malignant transformation. ${ }^{3}$

Histopathology of EAI-Histologically, later stages of EAI can demonstrate focal hyperkeratosis with dyskeratosis and increased dermal elastosis, similar to actinic damage, with a predisposition to develop SCC. ${ }^{2}$ Notably, early reports document various heat-induced carcinomas, including kangri-burn cancers among Kashmiris, kang thermal cancers in China, and kairo cancers in Japan., ${ }^{2,4}$ More recent reports identify cutaneous carcinomas arising specifically in the setting of EAI, most commonly $\mathrm{SCC}^{3}$; Merkel cell carcinoma and cutaneous marginal zone lymphoma are less commonly reported malignancies. ${ }^{6,7}$ Given the frequency of malignant transformation within sites of thermal exposure, chronic heat exposure may share a common pathophysiology with SCC and 
other neoplasms, including Merkel cell carcinoma and cutaneous marginal zone lymphoma.

SCC in Black Individuals-Squamous cell carcinoma is the most common skin cancer in Black individuals, with a notably higher incidence in high-risk subpopulations (immunosuppressed patients). Unlike White individuals, SCCs frequently occur in non-sun-exposed areas in Black individuals and are associated with unique risk factors, such as human papillomavirus, as demonstrated in Black transplant patients. ${ }^{8}$ A retrospective study examining the characteristics of SCC on the legs of Black individuals documented atypical hyperkeratotic neoplasms surrounded by abnormal pigmentation and mottling of surrounding skin. ${ }^{9}$ Morphologic skin changes could be the result of chronic thermal damage: Numerous patients reported a history of leg warming from an open heat source. Other patients had an actual diagnosis of EAI. The predilection for less-exposed skin suggests UV radiation (UVR) might be a less important predisposing risk factor for this racial group, and the increased mortality associated with SCC in Black individuals might represent a more aggressive nature to this subset of SCCs. ${ }^{9}$ Furthermore, infrared radiation (IRR), such as fires and coal stoves, might have the potential to stimulate skin changes similar to those associated with UVR and ultimately malignant changes.

Infrared Radiation-Compared to UVR, little is known about the biological effects of IRR (wavelength, $760 \mathrm{~nm}$ to $1 \mathrm{~mm}$ ), to which human skin is constantly exposed from natural and artificial light sources. Early studies have demonstrated the carcinogenic potential of IRR, observing an augmentation of UVR-induced tumorigenesis in the presence of heat. More recently, IRR was observed to stimulate increased collagenase production from dermal fibroblasts and influence pathways (extracellular signal-related kinases $1 / 2$ and p38 mitogen-activated protein kinases) in a similar fashion to UVB and UVA. ${ }^{10,11}$
Therefore, IRR might be capable of eliciting molecular responses comparable to those caused by UVR.

\section{Conclusion}

Although SCC in association with EAI is uncommon, historical reports of thermal cancers and scientific observations of IRR-induced biological and molecular effects support EAI as a predisposing risk factor for SCC and the important need for close monitoring by physicians. Studies are needed to further elucidate the pathologic effects of IRR, with more promotion of caution relating to thermal exposure.

\section{REFERENCES}

1. Milchak M, Smucker J, Chung CG, et al. Erythema ab igne due to heating pad use: a case report and review of clinical presentation, prevention, and complications. Case Rep Med. 2016;2016:1862480.

2. Miller K, Hunt R, Chu J, et al. Erythema ab igne. Dermatol Online J. 2011;17:28. Accessed December 10, 2020. https://escholarship .org/uc/item/47z4v01z

3. Wharton JB, Sheehan DJ, Lesher JL Jr. Squamous cell carcinoma in situ arising in the setting of erythema ab igne. J Drugs Dermatol. 2008;7:488-489.

4. Neve EF. Kangri-burn cancer. Br Med J. 1923;2:1255-1256.

5. Laycock HT. The kang cancer of North-West China. Br Med J. 1948;1:982

6. Wharton J, Roffwarg D, Miller J, et al. Cutaneous marginal zone lymphoma arising in the setting of erythema ab igne. J Am Acad Dermatol. 2010;62:1080-1081.

7. Jones CS, Tyring SK, Lee PC, et al. Development of neuroendocrine (Merkel cell) carcinoma mixed with squamous cell carcinoma in erythema ab igne. Arch Dermatol. 1988;124:110-113.

8. Pritchett EN, Doyle A, Shaver CM, et al. Nonmelanoma skin cancer in nonwhite organ transplant recipients. JAMA Dermatol. 2016;152:1348-1353.

9. McCall CO, Chen SC. Squamous cell carcinoma of the legs in African Americans. J Am Acad Dermatol. 2002;47:524-529.

10. Freeman RG, Knox JM. Influence of temperature on ultraviolet injury. Arch Dermatol. 1964;89:858-864.

11. Schieke SM, Schroeder P, Krutmann J. Cutaneous effects of infrared radiation: from clinical observations to molecular response mechanisms. Photodermatol Photoimmunol Photomed. 2003;19:228-234. 